\title{
Behavior of Geogrid Reinforced Foundation Systems Supported on Clay Subgrades of Different Strengths
}

\author{
Arghadeep Biswas $^{1}$ - Md. Asfaque Ansari ${ }^{2}$-Sujit Kumar Dash ${ }^{3}$ - A. Murali Krishna ${ }^{4}$
}

Received: 7 June 2015 / Accepted: 26 June 2015/Published online: 7 July 2015

(c) Springer International Publishing AG 2015

\begin{abstract}
This paper presents an experimental study investigating the behaviour of geogrid reinforced sand-clay foundation systems with clay subgrades of different strengths. Model tests were carried out on a circular footing of $150 \mathrm{~mm}$ diameter $(D)$ resting on $1 \times 1 \times 1 \mathrm{~m}$ foundation bed having clay subgrades of different undrained shear strengths $\left(c_{\mathrm{u}}\right)$, ranging from 7 to $60 \mathrm{kPa}$. Different series of laboratory model tests were performed on homogeneous and layered foundation systems. The layered systems were comprised of dense sand of varying layer thicknesses $(H=0.63-2.19 D)$ overlying the clay subgrades. Pressuresettlement responses obtained indicated that the foundation performances were largely influenced by footing settlement $(s / D \%)$, layer thickness $(H)$, and subgrade strengths $\left(c_{\mathrm{u}}\right)$. The results indicated that the planar geogrid reinforcement, placed at the sand-clay interface, can substantially improve
\end{abstract}

A. Murali Krishna

amurali@iitg.ac.in

Arghadeep Biswas

arghadeep.biswas@gmail.com

Md. Asfaque Ansari

asfaque06@yahoo.com

Sujit Kumar Dash

sujit@civil.iitkgp.ernet.in

1 Department of Civil Engineering, Jalpaiguri Govt. Engineering College, Jalpaiguri, West Bengal 735102, India

2 Department of Civil Engineering, Government Polytechnic, Gorakhpur, Uttar Pradesh 273012, India

3 Department of Civil Engineering, Indian Institute of Technology Kharagpur, Kharagpur, West Bengal 721 302, India

4 Department of Civil Engineering, Indian Institute of Technology Guwahati, Guwahati, Assam 781 039, India the performance of the foundation beds depending on layer thickness and subgrade strength. A maximum of about 5.6fold improvement in bearing capacity was observed in the study, for very soft clay subgrade of $7 \mathrm{kPa}$.

Keywords Foundation · Subgrade strength · Clay · Sand · Planar geogrid

\section{List of Symbols}

$c_{\mathrm{u}} \quad$ Undrained shear strength of clay $(\mathrm{kPa})$

$G \quad$ Specific gravity of sand and clay

$\varphi \quad$ Frictional angle of sand obtained from triaxial test

$\left({ }^{\circ}\right)$

$C_{\mathrm{u}} \quad$ Coefficient of uniformity of the sand (dimensionless)

$C_{\mathrm{c}} \quad$ Coefficient of curvature of the sand (dimensionless)

$\gamma_{\mathrm{d} \text {, max }}$ Maximum dry unit weight of the sand $\left(\mathrm{kN} / \mathrm{m}^{3}\right)$

$H \quad$ Thickness of unreinforced and geocell-reinforced sand layer $(\mathrm{m})$

$D \quad$ Diameter of the model footing (m)

$D_{\mathrm{r}} \quad$ Relative density of sand (dimensionless)

$s \quad$ Footing settlement (m)

$\delta \quad$ Surface deformation (m)

$q_{\mathrm{c}} \quad$ Bearing pressure of homogeneous clay bed (kPa)

$q_{\mathrm{s}} \quad$ Bearing pressure of unreinforced layered foundations $(\mathrm{kPa})$

$q_{\mathrm{sg}} \quad$ Bearing pressure of geogrid reinforced foundations $(\mathrm{kPa})$

$I_{\mathrm{fs}} \quad$ Bearing pressure improvement factor: $q_{\mathrm{s}} / q_{\mathrm{c}}$ (dimensionless)

$I_{\mathrm{fsg}} \quad$ Bearing pressure improvement factor: $q_{\mathrm{sg}} / q_{\mathrm{c}}$ (dimensionless)

$I_{\mathrm{fg}} \quad$ Bearing pressure improvement factor: $q_{\mathrm{sg}} / q_{\mathrm{s}}$ (dimensionless) 


\section{Introduction}

Soil reinforcement technology is given the utmost importance in present days to adapt week soil into the competent stable ground for different civil engineering applications. It was started with Vidal [1] and became familiar with the pioneer work of Binquet and Lee [2]. Strip-metallic reinforcements, in the beginning, were replaced by geosynthetics in different forms such as sheet-type (planar) geotextile, geogrid, and three dimensional geocells. The beneficial effects of planar reinforcements in foundation applications, considering various aspects such as reinforcement strength and geometry, depths of placement, and number of layers etc., have been studied and demonstrated by several investigators [3-6]. Different parametric investigations were performed through physical and/or analytical model tests for the last few decades [7-29]. Most of researches reported so far, on geogrid-reinforced foundations, were focused on improving the 'weak soil', either soft clay of $c_{\mathrm{u}} \leq 15 \mathrm{kPa}$ or loose sand having $D_{\mathrm{r}} \leq 60 \%$, by varying different parameters.

In practice, situations may arise where reasonably strong soil also fails to meet the design requirements or marginally competent ground needs to be improved. However, comparative performance improvement due to geogrid reinforced systems, in the context of different clay subgrades, hasn't been explicitly studied. Recently, Biswas et al. [30] presented the effect of subgrade strength on the performance of geocell reinforced foundations.

Present study envisages to develop an understanding of the performance of geogrid reinforced foundation systems having clay subgrades of different undrained shear strengths $\left(c_{\mathrm{u}}\right)$ of $7,15,30$, and $60 \mathrm{kPa}$. Different series of physical model tests have been conducted by varying different parameters such as the soil configuration (i.e. homogeneous and layered) with reinforcement systems. The results have been analyzed to understand the behavior of the reinforced foundation systems and to bring out the effect of subgrade strength on improvement levels.

\section{Testing Program}

A typical geogrid-reinforced layered foundation system $(1 \times 1 \times 1 \mathrm{~m})$ with a circular footing of diameter $D$, considered in the present study, is shown in Fig. 1. Two types of soils are shown: top fill soil is sand and bottom native soil is clay. Planar geogrid reinforcement was placed at the sand-clay interface. The thickness of the sand layer and width of the geogrid are represented as ' $H$ ' and ' $b$ ', respectively. The details of test program are presented in Table 1. One series of tests on homogenous systems (series A) and two series of tests on layered systems (unreinforced-series B and reinforcedseries $\mathrm{C}$ ), having sand layer of varying thicknesses overlying

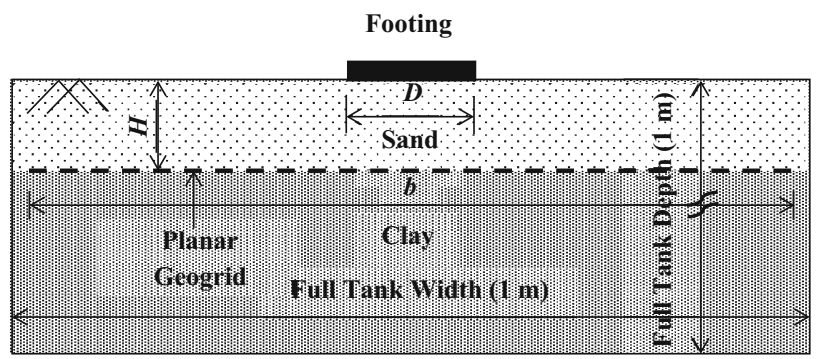

Fig. 1 Schematic geomrtric configuration of geogrid-reinforced foundation systems

the clay subgrades of different strengths as shown in Table 1, were conducted. In layered foundations, except subgrade strengths and the layer thicknesses, other parameters such as width of the geogrid $(b)$ and relative density $\left(D_{\mathrm{r}}\right)$ of sand were kept constant at $6 D$ and $80 \%$, respectively.

\section{Materials Used}

A steel circular plate of $150 \mathrm{~mm}$ diameter $(D)$ and $18 \mathrm{~mm}$ thickness was used as the model footing. The foundation beds with clay and/or sand were prepared with locally available red clayey soil and river sand. A biaxial geogrid was used at the sand-clay interface to reinforce the foundations. The details of material properties obtained from laboratory are summarized in Table 2 .

\section{Test Setup and Methodology}

The schematic diagram of the test setup is shown in Fig. 2 . Laboratory model foundation beds were prepared in a heavily braced steel test tank of dimension $1 \times 1 \times 1 \mathrm{~m}$. The tank was provided with a loading frame to load the footing through a manually operated hydraulic jack of $100 \mathrm{kN}$ capacity. A precalibrated proving ring was used to measure the magnitude of the load transferred onto the footing.

Foundation beds were prepared in two steps: (1) preparation of clay beds/subgrades and (2) preparation of sand bed/layer overlying the clay subgrades. A calibration curve (Fig. 3) showing the variation of undrained shear strength $\left(c_{\mathrm{u}}\right)$ with water content (for uniform compaction effort) was obtained by conducting several trial tests. For the desired strength $\left(c_{\mathrm{u}}=7,15,30\right.$ and $\left.60 \mathrm{kPa}\right)$, the required moisture content and density were obtained from the calibration curve. The sand bed was prepared through pluviation technique. Relative density of the sand was kept constant at $80 \%$ throughout the testing program. For sand raining, the required height of fall to achieve the desired density was determined through several trials. For the reinforced case, sand raining was started after placing the geogrid over the clay subgrade. 
Table 1 Details of the testing program

\begin{tabular}{llll}
\hline Test series & Foundation configurations & Test parameters & Constant parameters \\
\cline { 3 - 4 } & & Variable parameters & - \\
\hline A & Homogeneous clay & $c_{\mathrm{u}}=7,15,30$, and $60 \mathrm{kPa}$ & $D_{\mathrm{r}}=80 \%$ \\
& Homogeneous sand & - & $D_{\mathrm{r}}=80 \%, b / D=6$ \\
B & Sand bed overlying clay subgrade & $c_{\mathrm{u}}=7,15,30$, and $60 \mathrm{kPa}$ & 16 \\
& & $H=0.63,1.15,1.67$, and $2.19 D$ & \\
C & Sand bed overlying clay subgrade with & $c_{\mathrm{u}}=7,15,30$, and $60 \mathrm{kPa}$ & $D_{\mathrm{r}}=80 \%, b / D=6$ \\
& planar geogrid at the interface & $H=0.63,1.15,1.67$, and $2.19 D$ & \\
\hline
\end{tabular}

Table 2 Material properties

\begin{tabular}{llll}
\hline Parameters & \multicolumn{3}{l}{ Materials } \\
\cline { 2 - 4 } & Clay & Sand & Geogrid \\
\hline$G$ & 2.65 & 2.68 & - \\
LL $(\%)$ & 42 & - & - \\
PL $(\%)$ & 21 & - & - \\
$\gamma_{\mathrm{d}, \max }\left(\mathrm{kN} / \mathrm{m}^{3}\right)$ & 20.71 & - & - \\
OMC $(\%)$ & 19.31 & - & - \\
$D_{\mathrm{r}}(\%)$ & - & 80 & - \\
$\varphi^{\circ}$ & - & 40 & - \\
$C_{\mathrm{u}}$ & - & 3.06 & - \\
$C_{\mathrm{c}}$ & - & 0.62 & - \\
Ult. tensile strength $(\mathrm{kN} / \mathrm{m})$ & - & - & 20 \\
Failure strain $(\%)$ & - & - & 11 \\
Secant modulus (at $5 \%$ strain) & - & - & 240 \\
$\quad(\mathrm{kN} / \mathrm{m})$ & & &
\end{tabular}

After preparing the foundation bed to its full height, the footing was placed at the center of the leveled surface. The instrumentations (dial gauges, $D_{\mathrm{g} 1}-D_{\mathrm{g} 8}$ in Fig. 2) were suitably positioned and the footing was loaded through the hydraulic jack, by pushing it into the soil, at a rate of about $3 \mathrm{~mm} / \mathrm{min}$. Comparatively, faster rate of loading was considered to simulate 'undrained condition' in saturated clay [6, 31]. The responses of the model foundations were monitored at different loading stages by recording the footing settlement and deformations (heave or settlement) at different locations on the foundation surface $(D, 2 D$, and $3 D$ from the center of the footing on either side) with eight dial gauges of $0.01 \mathrm{~mm}$ accuracy. During loading, measurements from the dial gauges and load on the proving ring were recorded at equal intervals of footing settlements $(1 \mathrm{~mm})$ until $24 \%$ of ' $D$ '.

\section{Results}

Test results are presented in terms of pressure-settlement responses of different foundation configurations having varying layer thicknesses $(H)$ and subgrade strengths $\left(c_{\mathrm{u}}\right)$.
The pressure-settlement responses are further analyzed in terms of bearing pressure ratios (improvement factors), defined to quantify the improvement of different foundation configurations as compared to homogeneous foundations. The improvement factors are defined as the ratio of two bearing pressures, at similar levels of footing settlements $(s / D)$, as presented in Eqs. 1 and 2. In the equations, $q_{\mathrm{s}}$ and $q_{\mathrm{sg}}$ are the bearing pressures of unreinforced and geogrid reinforced layered foundations, respectively; whereas, $q_{\mathrm{c}}$ is the bearing pressure of corresponding homogeneous clay beds. Besides, the foundation behavior was further discussed with respect to surface deformation $(\delta)$ variations.

$I_{\mathrm{fs}}=\left(\frac{q_{\mathrm{s}}}{q_{\mathrm{c}}}\right) \quad[$ at same level of $s / D]$

$I_{\mathrm{fsg}}=\left(\frac{q_{\mathrm{sg}}}{q_{\mathrm{c}}}\right) \quad[$ at same level of $s / D]$

To evaluate the contribution of planar geogrid reinforcement in the foundation performance another factor $I_{\mathrm{fg}}$ was evaluated as per the Eq. 3 .

$I_{\mathrm{fg}}=\left(\frac{q_{\mathrm{sg}}}{q_{\mathrm{s}}}\right) \quad[$ at same level of $s / D]$

\section{Homogeneous Foundations (Clay and Sand)}

In series A, tests were performed on homogeneous foundations of clay having different undrained shear strengths $\left(c_{\mathrm{u}}=7,15,30\right.$, and $\left.60 \mathrm{kPa}\right)$ and sand at dense state $\left(D_{\mathrm{r}}=80 \%\right)$. The bearing pressure-footing settlement responses of these homogeneous clay beds are presented in Fig. 4. It can be noticed that the variation in bearing pressures with footing settlements were non-linear and none of the four clay bed response curves showed peak values within the range of settlements tested (up to $s / D=24 \%$ ). Higher pressure-settlement responses were obtained for clay beds having higher ' $c_{\mathrm{u}}$ '. The maximum bearing pressure of about $31 \mathrm{kPa}$ for $c_{\mathrm{u}}=7 \mathrm{kPa}$ and about $245 \mathrm{kPa}$ for $c_{\mathrm{u}}=60 \mathrm{kPa}$ can be noted from the response curves (at $s / D=24 \%$ ). At $s / D=2 \%$, the bearing pressure for very soft clay bed $\left(c_{\mathrm{u}}=7 \mathrm{kPa}\right)$ was $17.5 \mathrm{kPa}$, 
Fig. 2 Schematic configurations of test set-up

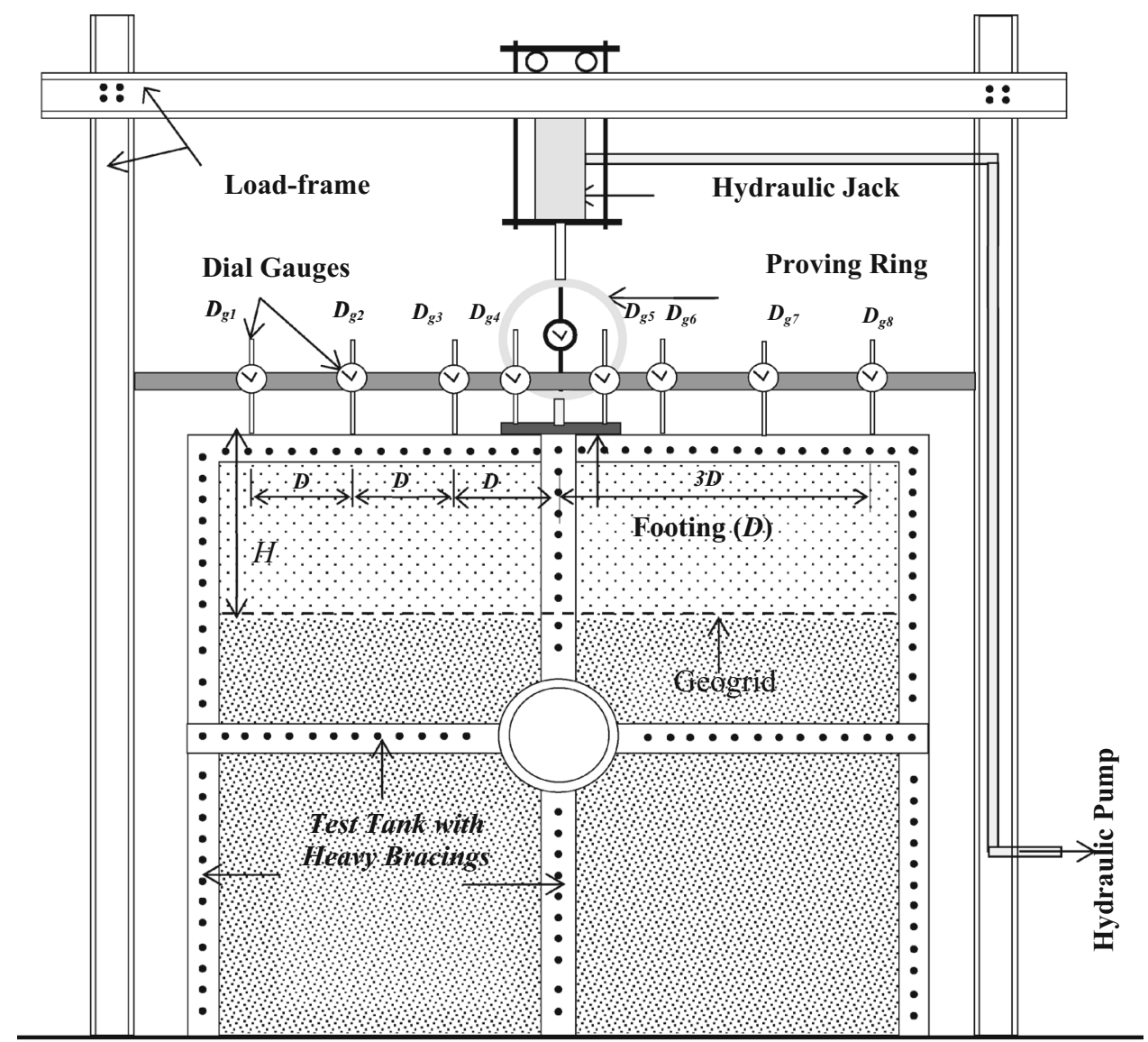

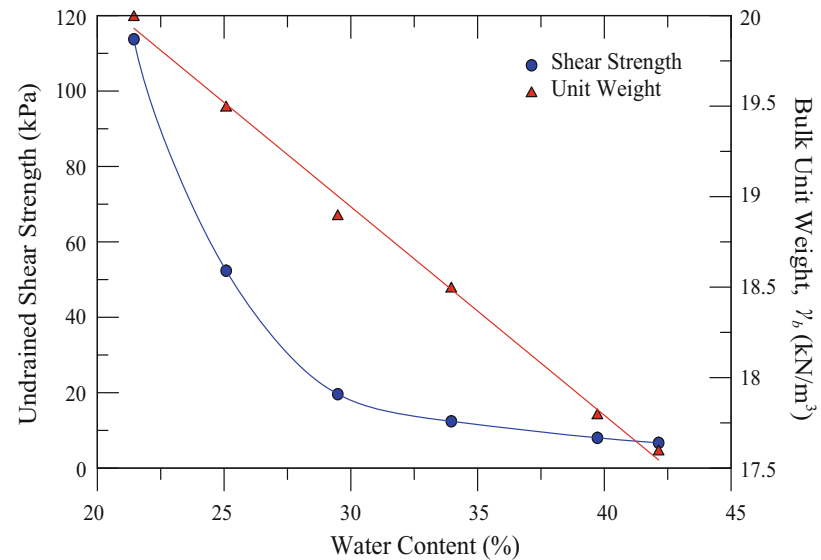

Fig. 3 Calibration curves for clay

whereas it was $84 \mathrm{kPa}$ for stiff clay $\left(c_{\mathrm{u}}=60 \mathrm{kPa}\right)$. The corresponding pressure values at $s / D=12 \%$ were 31.4 and $196 \mathrm{kPa}$, respectively.

The response of the homogeneous sand bed $\left(D_{\mathrm{r}}=\right.$ $80 \%$ ) is also presented in Fig. 4 (dashed line). It is seen that the bearing pressure of the sand bed increased to about $175 \mathrm{kPa}($ at $s / D=18 \%)$ and then it became almost constant with footing settlement. In comparison with the

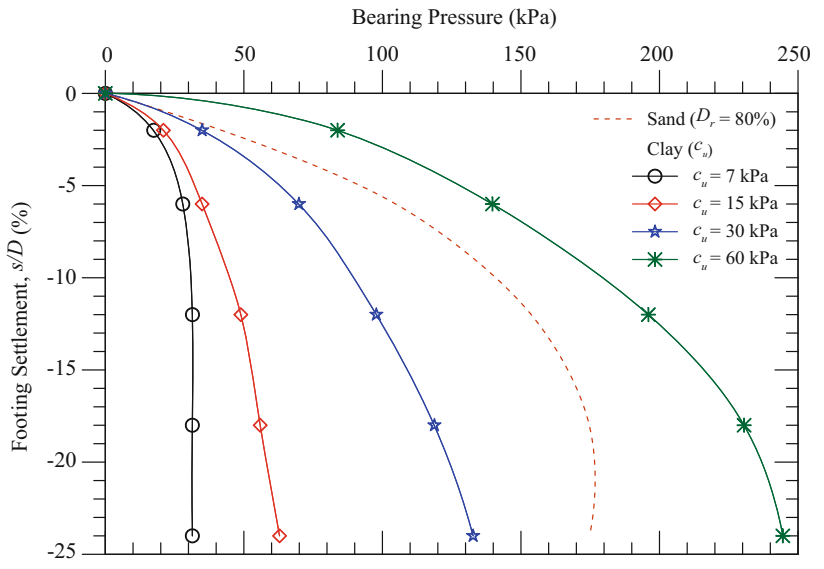

Fig. 4 Pressure-settlement responses of homogeneous beds: clay and sand

homogeneous clay bed responses, it is noted that clay beds having $c_{\mathrm{u}} \leq 30 \mathrm{kPa}$ depicted softer response (less bearing pressure) than that of the sand bed. Further, it is to be noted that the sand bed showed softer response relative to the clay bed with $c_{\mathrm{u}}=60 \mathrm{kPa}$.

The average surface deformations $(\delta / D)$ of the homogeneous foundations, at $x=D$ from the footing center, are presented in Fig. 5. Though the trends are not very 


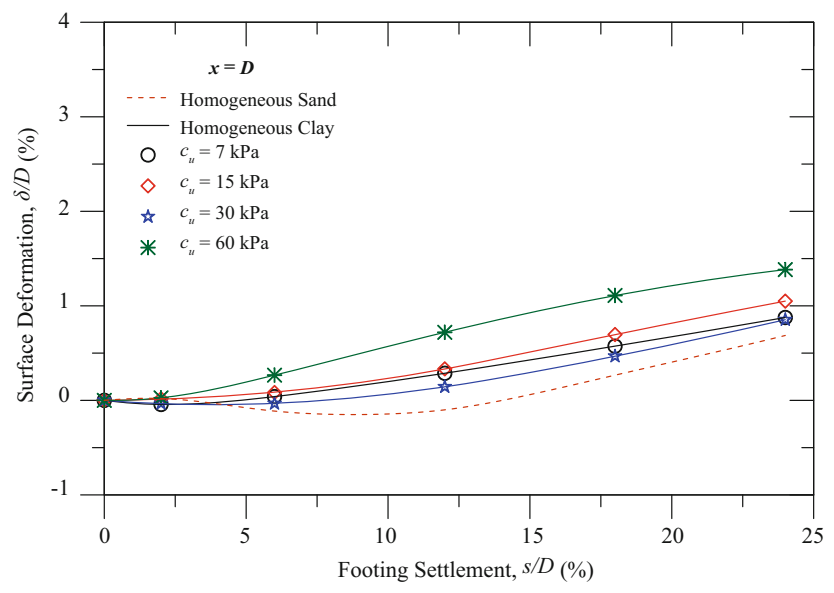

Fig. 5 Variation in average surface deformation at $x=D$ for homogeneous beds

consistent with the clay strength, the variations are showing predominantly heaving for the clay beds $[6,30,31]$. The pronounced heaving is attributed to the undrained behavior of the saturated clay which was generated with the faster rate of loading. The deformation response of the sand bed, presented in dotted lines, indicated an initial settlement (up to $s / D \sim 15 \%$ ) followed by heaving at the foundation surface. The maximum settlement $(-\delta / D)$ was about $0.15 \%$ at $s / D=6 \%$ and maximum heaving $(+\delta / D)$ was about $0.6 \%$ at $s / D=24 \%$. This behavior could be attributed with the dilation of dense sand. However, away from the footing center $(x \geq 2 D)$, marginal deformations were seen for all the homogeneous foundation beds.

\section{Unreinforced Layered Foundation Systems (Clay + Sand)}

Model tests on layered foundations having varying thicknesses of unreinforced sand $(H=0.63,1.15,1.67$, and $2.19 D)$ overlying clay subgrades of different strengths $\left(c_{\mathrm{u}}\right)$ were performed in series $\mathrm{B}$. The pressure-settlement responses of the layered foundations of $c_{\mathrm{u}}=7 \mathrm{kPa}$ are presented in Fig. 6. Increase in bearing pressures from 31 to $56 \mathrm{kPa}$ at $s / D=24 \%$ can be noticed from the figure, for clay subgrades of $c_{\mathrm{u}}=7 \mathrm{kPa}$, with $0.63 \mathrm{D}$ thick sand layer. Besides, higher pressure values were noticed with increase in layer thicknesses $(H)$. The bearing pressures were increased from 56 to $168 \mathrm{kPa}$ with an increase in thickness from 0.63 to $2.19 D$, for $c_{\mathrm{u}}=7 \mathrm{kPa}$ (at $s / D=24 \%)$. However, reduction in improvement rate was noticed beyond a layer thickness of $H=1.67 D$. In Fig. 6, an increase in bearing pressure of about 161-168 kPa can be noted for an increase in $H$ from 1.67 to $2.19 D$; whereas, the increase was in the range of 56 to $161 \mathrm{kPa}$ for $H=0.63$ to $1.67 D$ (at $s / D=24 \%$ ). Similar variations in foundation performance improvement were

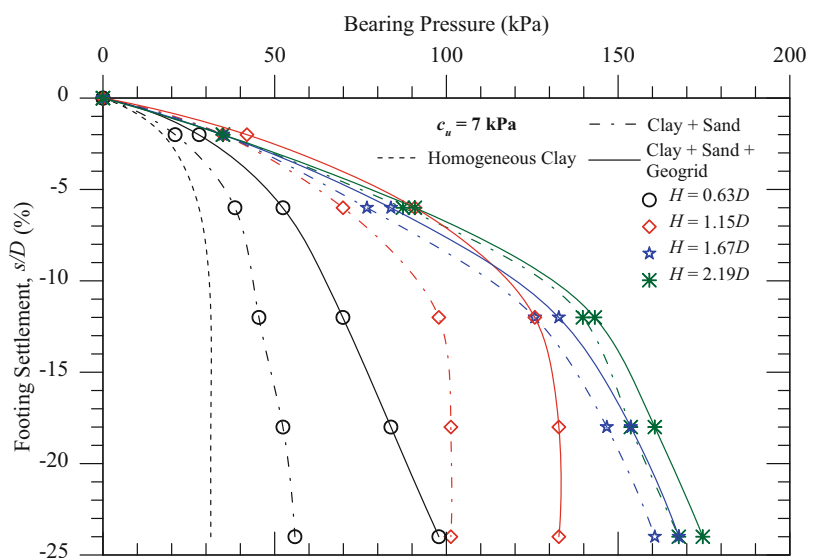

Fig. 6 Pressure-settlement responses of different foundation systems with $c_{\mathrm{u}}=7 \mathrm{kPa}$

also observed for subgrades of $c_{\mathrm{u}}=15$ and $30 \mathrm{kPa}$. From the observations, the optimum thickness for the layered configuration can be considered as $H=1.67 D$ which could derive maximum contribution from the clay subgrade and the overlying sand layer.

Responses of unreinforced layered foundations with stiff clay subgrade $\left(c_{\mathrm{u}}=60 \mathrm{kPa}\right)$ are presented in Fig. 7. It can be seen that all the responses are lesser than the homogeneous clay bed and are very much similar to each other irrespective of sand layer thickness variations. A minor difference is noted at $H=0.63 D$ with a maximum bearing pressure of $203 \mathrm{kPa}$. However, beyond $H$ of $1.15 D$, the responses remained almost unchanged with maximum bearing pressure of about $190 \mathrm{kPa}$. The increased bearing pressure with $H$ of $0.63 D$ is the effect of additional support derived from the underlying stiff clay. For a relatively thin layer of sand $(H \leq D)$, such as $0.63 D$, the failure surface extended to the underlying stiff clay subgrade which provided higher resistance. Whereas, for the thick layers $(>D)$, the failure surface develops within the sand layer and the layered responses are dominated by the sand behavior. Similar foundation behaviors for softer layer overlying stiffer subgrade and vice versa were also reported by Meyerhof [32].

\section{Layered Foundation Systems (Clay + Sand + Geogrid)}

Behavior of layered foundations having a planar geogrid at the sand-clay interface, were investigated in test series C. The foundation configurations were kept similar to that in series $\mathrm{B}$, except placing a planar geogrid of width ' $b$ ', at the two layers interface. The pressure-settlement responses of geogrid-reinforced foundations with $c_{\mathrm{u}}=7$ and $60 \mathrm{kPa}$ are presented in Figs. 6 and 7, respectively. Responses of the corresponding homogeneous clay bed (series A) are also 


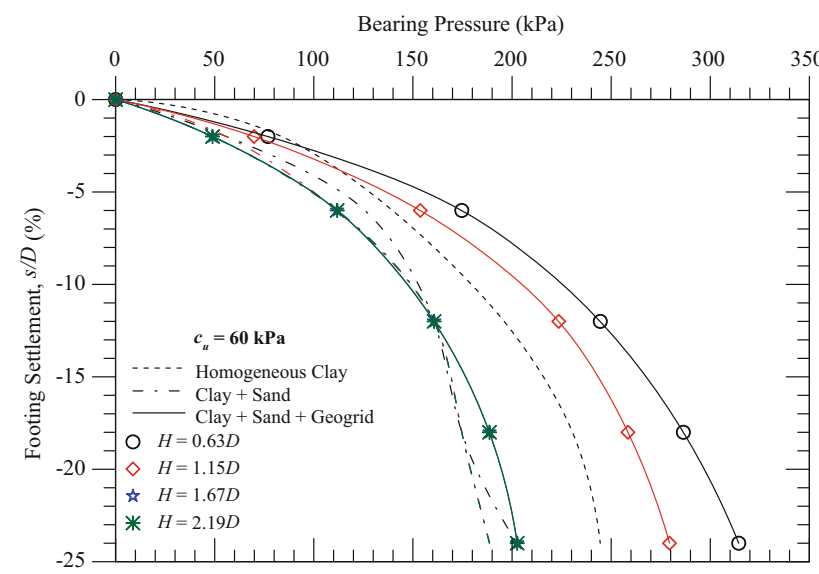

Fig. 7 Pressure-settlement responses of different foundation systems with $c_{\mathrm{u}}=60 \mathrm{kPa}$

provided in the figures. The maximum bearing pressure for geogrid-reinforced system with very soft clay subgrade $\left(c_{\mathrm{u}}=7 \mathrm{kPa}\right)$ at $s / D=24 \%$ is $175 \mathrm{kPa}$ (at $\left.H=2.19 D\right)$, while the corresponding value was $31 \mathrm{kPa}$ for the homogeneous clay bed and $168 \mathrm{kPa}$ for unreinforced layered bed. In the case of stiff clay subgrade $\left(c_{\mathrm{u}}=60 \mathrm{kPa}\right)$, the reinforced beds showed (Fig. 7) higher performance up to $H \leq 1.15 D$ (compared to the homogenous bed), for $s / D$ in the range $2-18 \%$.

In Fig. 8, a comparison of average surface deformation (at $x=D, 2 D$, and $3 D$ ) for the unreinforced foundation ( $c_{\mathrm{u}}=7 \mathrm{kPa}$ at $H=0.63 D$ ) and the corresponding homogeneous clay bed is presented. It is observed that the surface heaving was reduced for unreinforced layered foundations as compared to the homogeneous clay beds.

\section{Discussion}

Pressure-settlement responses presented above indicate that the foundation performances were largely influenced by footing settlement $(s / D \%)$, layer thickness $(H)$, and subgrade strengths $\left(c_{\mathrm{u}}\right)$. The following sections provide discussions on the effects of these parameters. In general, significant improvements in bearing pressures are seen with geogrid-reinforcement (series $\mathrm{C}$ ) as compared to the corresponding unreinforced layered systems (series B).

\section{Effect of Footing Settlement}

Greater improvement in bearing pressure was noticed in Fig. $6\left(c_{\mathrm{u}}=7 \mathrm{kPa}\right)$, at higher settlement levels. For instance, at $H=0.63 D$ and $s / D=6 \%$, about 1.4 times higher bearing pressure is seen for the geogrid-reinforced system ( $\sim 52 \mathrm{kPa})$, as compared to the corresponding value

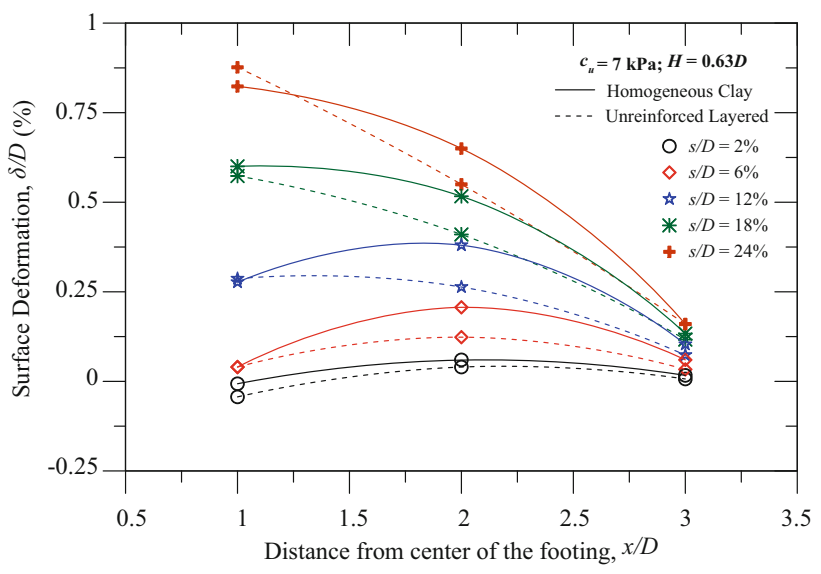

Fig. 8 Surface deformations with footing settlement for homogeneous and unreinforced layered foundation on $c_{\mathrm{u}}=7 \mathrm{kPa}$ $(H=0.63 D)$

of unreinforced system $(\sim 38 \mathrm{kPa})$. In similar layer configuration, the variations in bearing pressures for geogrid reinforced foundation is about $70-98 \mathrm{kPa}$, in the settlement range $12-24 \%$ of $s / D$; while, the corresponding values of the unreinforced system is $45-56 \mathrm{kPa}$, respectively.

The improvement factors for layered systems are evaluated as per Eqs. 1 and 2. The $I_{\mathrm{fs}}$ values for softer subgrades $\left(c_{\mathrm{u}} \leq 30 \mathrm{kPa}\right)$ are ranging from 1.2 to 5.34 signifying considerable improvements as compared to corresponding homogeneous clay beds. A typical variation of improvement factors with footing settlement for different layered configurations having the clay subgrades of 7 and $60 \mathrm{kPa}$ are presented in Fig. 9. It is observed that the improvement factors are enhanced with increase in layer thickness $(H)$ and footing settlement $(s / D)$ for the very soft clay subgrade $\left(c_{\mathrm{u}}=7 \mathrm{kPa}\right)$. In this case, the $I_{\mathrm{fs}}$ varied from 1.78 to 5.34 for an increase in layer thickness from 0.63 to $2.19 D($ at $s / D=24 \%)$. However, beyond a thickness of $1.15 D$ and a settlement level of $s / D \geq 12 \%$, the rate of improvements $\left(I_{\mathrm{fs}}\right)$ were reduced which is represented by flatter slopes. At similar conditions, the $I_{\mathrm{fs}}$ for the subgrades having $c_{\mathrm{u}}=15$ and $30 \mathrm{kPa}$ are found to be varied as 2.22-2.67 and 1.21-1.63, respectively. This could be attributed to the punching of sand layer into the softer subgrades which increases the influence of softer clay underneath. Besides, the local shear and squeezing out of the sand layer from the footing bottom resulted in higher settlement which reduced the overall performance improvement. In the case of $c_{\mathrm{u}}=60 \mathrm{kPa}$, the improvement factors are in the range of $0.58-0.90$ indicating reduced performance as compared to the corresponding homogeneous clay bed which is due to softer sand layer over the stiff clay subgrade. Besides, it can be noticed that for $s / D>6 \%$, the improvement factors are almost remain the same. 


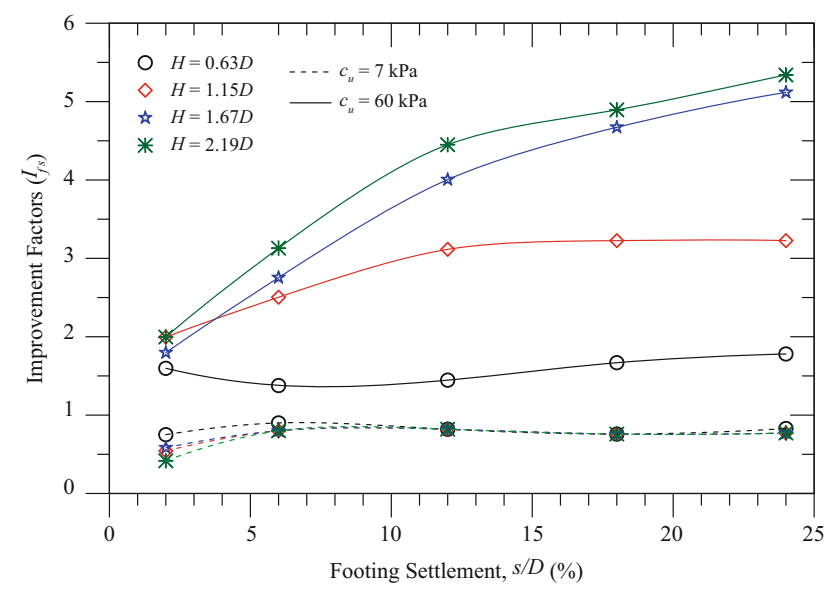

Fig. 9 Variation of $I_{\mathrm{fs}}$ with $s / D$ for $c_{\mathrm{u}}=7$ and $60 \mathrm{kPa}$ with varying $H / D$

Variation of improvement factors, $I_{\mathrm{fsg}}$ and $I_{\mathrm{fg}}$, with footing settlements are presented in Fig. 10, for $c_{\mathrm{u}}=7 \mathrm{kPa}$. It is seen that both the improvement factors are increased with footing settlements. However, for $H>0.63 D$, reduction in the rate of improvements is observed at $s / D \geq 12 \%$, which is indicated by a flatter slope. The reduction was due to punching of the sand column into the subgrade and squeezing out of the sand layer from the footing bottom. Hence, the footing had undergone localized settlement without generating sufficient additional beneficial effects out of the interface-geogrid.

Improved performances in bearing pressures with increase in footing settlements for reinforced foundations are attributed to the 'membrane resistance' mobilized along the planar geogrid [3, 8] which is expected to increase with deformations at the interface. However, in the present test program, no deformation measurements regarding this were available; but post-test exhumations indicated visible deformations of clay subgrades. Besides, impressions of geogrid apertures were observed on the clay subgrade, indicating that interlocking took place during footing settlement through the clay subgrade. Similar deformation observations at the interface and interlocking aspects were also reported by Love et al. [3].

In Fig. 11, a typical surface deformations at $x=D, 2 D$, and $3 D$ are presented for unreinforced and geogrid reinforced foundations $\left(c_{\mathrm{u}}=7 \mathrm{kPa} ; H=0.63 D\right)$ at different levels of footing settlement. The deformation response of corresponding homogeneous bed is also presented for comparison. The responses, though not very consistent with respect to distance from footing center, depicted mostly heaving on foundation surface at $x=D$ and $2 D$ and enhanced with footing settlements. It is attributed to the combined effect of undrained behavior of saturated clay and dilation of the dense sand. However, at $x=3 D$, variation in surface deformation

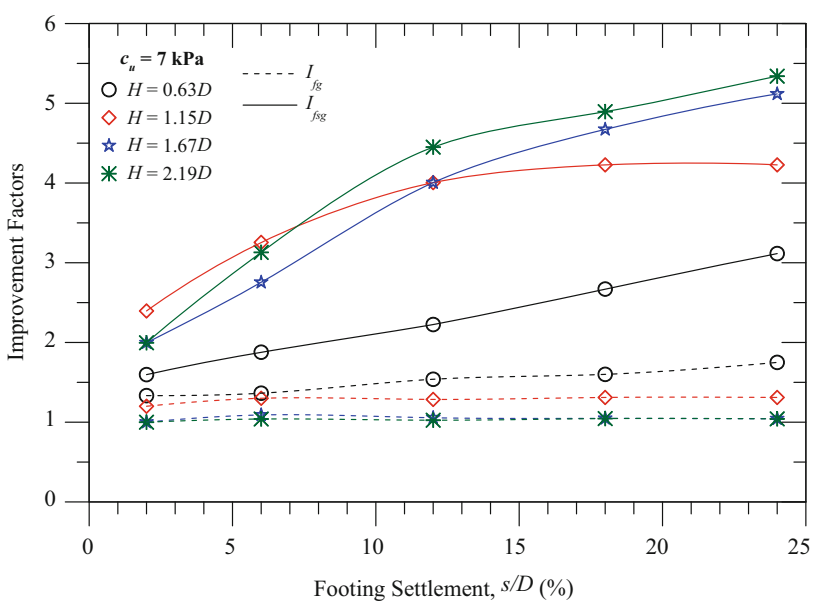

Fig. 10 Variation of $I_{\mathrm{fsg}}$ and $I_{\mathrm{fg}}$ with $s / D(\%)$ at different $H / D$ for $c_{\mathrm{u}}=7 \mathrm{kPa}$

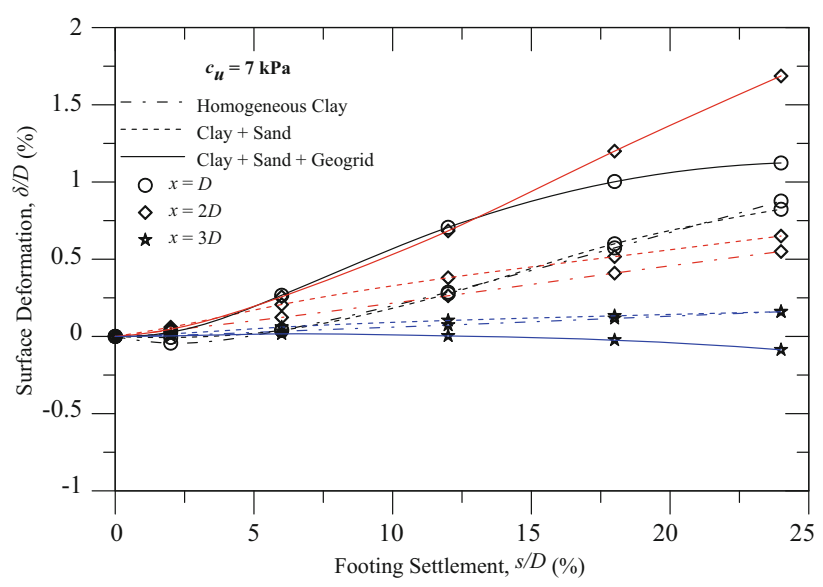

Fig. 11 Typical surface deformations at $x=D, 2 D$ and $3 D$, for $c_{\mathrm{u}}=7 \mathrm{kPa}(H=0.63 D)$

was negligible with respect to foundation configurations. Marginal surface settlement at $x=3 D$ can be noticed in Fig. 11, for geogrid-reinforced foundation. It is due to the interlocking of sand layer with the grids while moving-in toward footing center upon loading. In general, increasing surface deformation with footing settlement is observed for different foundations having varying layer configurations and subgrade strengths.

\section{Effect of Layer Thickness (H)}

The pressure-settlement responses have indicated that the sand layer thicknesses $(H)$, in the range of $0.63 D$ to $2.19 D$, significantly affected the foundation behavior at a given footing settlement. In Fig. 6, bearing pressures at $s / D=12 \%$ for $c_{\mathrm{u}}=7 \mathrm{kPa}$ is enhanced from $70 \mathrm{kPa}$ to 126 , 133 , and $143 \mathrm{kPa}$ for the layer thickness $(H)$ variation from 
0.63 to $1.15,1.67$, and $2.19 D$, respectively. In this case bearing pressures were improved with increase in $H / D$ values. However, this is not true at the other settlement levels (such as $s / D=2$ and $6 \%)$ and for other $c_{\mathrm{u}}$ subgrades $\left(c_{\mathrm{u}}=15\right.$ and $30 \mathrm{kPa})$. For comparatively stiffer subgrades $\left(c_{\mathrm{u}}=15\right.$ and $30 \mathrm{kPa}$ ), a reduction in the rate of improvement can be observed for thicker layers $(H \geq 1.67 D)$; while, reduction in pressure values are noticed for the stiff clay subgrade $\left(c_{\mathrm{u}}=60 \mathrm{kPa}\right)$ for $H \geq 1.15 \mathrm{D}$. This can be attributed to the insufficient strain generated at geogrid to derive the membrane resistance which can be the result of the followings: squeezing out of sand from footing bottom and the reduction in pressure intensity with increased layer thickness.

In Fig. 12, the effect of layer thicknesses $(H)$ is presented, in the form of typical variations in improvement factors $\left(I_{\mathrm{fs}}\right)$, at the maximum footing settlement level $(s / D=24 \%)$. In general, for softer subgrades $\left(c_{\mathrm{u}} \leq 30 \mathrm{kPa}\right)$ the improvement factors were increased with increase in layer thickness up to about $1.67 D$. The maximum value of $I_{\mathrm{fs}}$ can be noted as about 5.34, 2.67, and 1.63 for the subgrades having $c_{\mathrm{u}}=7,15$, and $30 \mathrm{kPa}$, respectively, at $2.19 D$; whereas, for $c_{\mathrm{u}}=60 \mathrm{kPa}$, the responses were almost constant irrespective of layer thickness variation which could be seen by the bearing pressure ratio of around 0.80 .

Variations in improvement factors, $I_{\mathrm{fsg}}$ and $I_{\mathrm{fg}}$, with change in layer thickness for different subgrades, at two different levels of footing settlement $(s / D=12$ and $24 \%)$, are presented in Fig. 13. The figure depicts that the layer thickness is significantly influencing the improvement for very soft subgrade $\left(c_{\mathrm{u}}=7 \mathrm{kPa}\right)$; while, the effect is marginal for other subgrades. For very stiff subgrade, $c_{\mathrm{u}}=60 \mathrm{kPa}$, the layer thickness showed a negative effect. The improvement factor $I_{\mathrm{fg}}\left(q_{\mathrm{sg}} / q_{\mathrm{s}}\right)$, showing the geogrid-contribution, is also depicted a decreasing trend with increase in layer thickness. The $I_{\mathrm{fg}}$ is found to be in the range of 1.0-1.75. The $I_{\mathrm{fg}}$ values approached 1.0 indicating no geogrid contribution beyond a thickness of 1.67D. This behaviour can be inferred due to the fact that, as geogrid placement depth increases the reinforcement effect decreases $[10,13,16]$. Further, as typical foundation systems show significant depth about 1-1.5 times diameter/width of the footing [33, 34], the geogrid placed at a depth on/and beyond $1.67 D$ showed practically no contribution.

\section{Effect of Subgrade Strengths $\left(c_{\mathrm{u}}\right)$}

The influence of different subgrades $\left(c_{\mathrm{u}}\right)$ on overall foundation performance is presented in Fig. 14, in terms of improvement factors $\left(I_{\mathrm{fs}}\right)$, for $H=2.19 \mathrm{D}$. In general, a decreasing trend in improvement factors with increasing subgrade strength can be noticed which was significantly high at higher level of settlement, such as $s / D=24 \%$. The $I_{\mathrm{fs}}$ values decreased from 5.34 to 0.77 for an increase in $c_{\mathrm{u}}$ from 7 to $60 \mathrm{kPa}$ at $s / D=24 \%$. In this regard, it should be mentioned here that

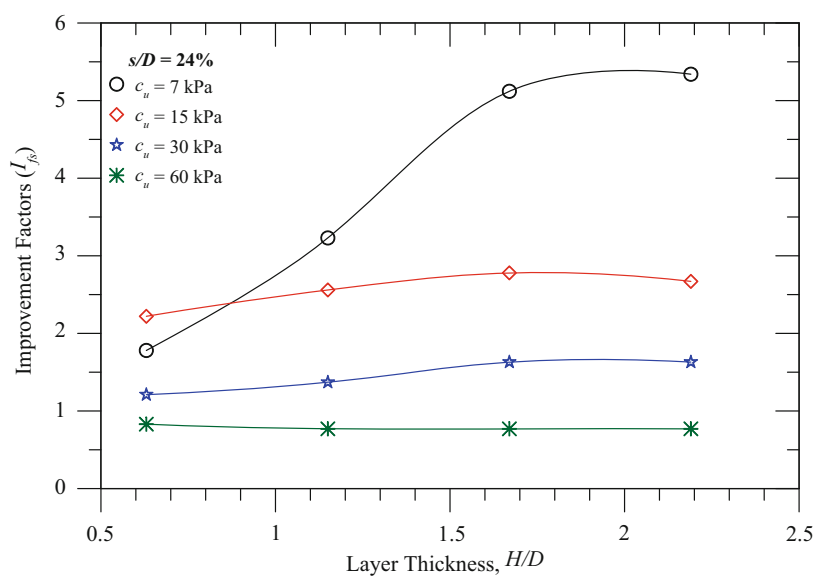

Fig. 12 Variation of $I_{\mathrm{fs}}$ with layer thickness $(H)$ for different $c_{\mathrm{u}}$ at $s / D=24 \%$

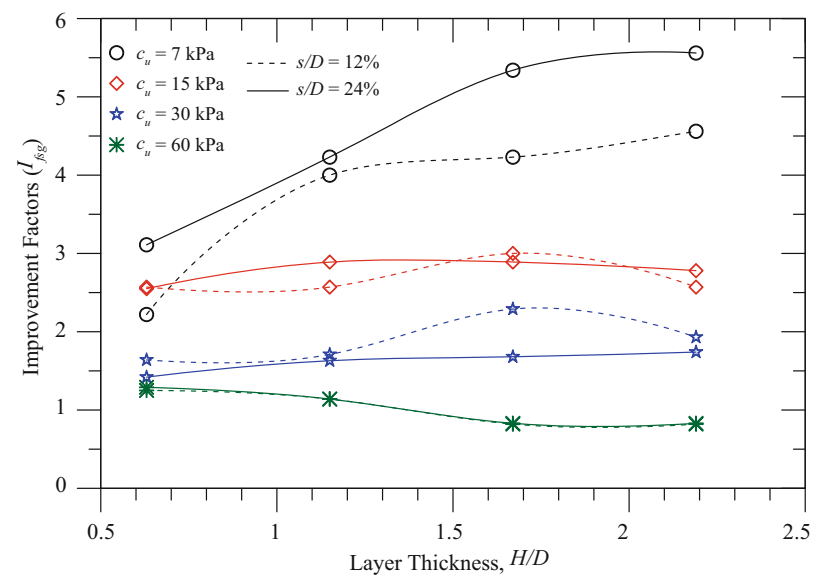

Fig. 13 Effect of layer thickness $(H)$ in terms of $I_{\mathrm{fsg}}$ at $s / D=12$ and $24 \%$

the decreasing trend is in terms of improvement factors only; however, the corresponding bearing pressures were still increasing with the subgrade strengths.

Pressure-settlement responses of the unreinforced and geogrid-reinforced layered foundation configurations, at $H=0.63 D$ with different subgrades $\left(c_{\mathrm{u}}\right)$, are presented in Fig. 15. For all the clay subgrades, geogrid-reinforced foundations showed higher bearing pressures compared to the corresponding unreinforced systems. The bearing pressure of unreinforced layered foundation are about 45, 112, 145 , and $161 \mathrm{kPa}$ for $c_{\mathrm{u}}=7,15,30$, and $60 \mathrm{kPa}$, respectively, at $s / D=12 \%$. The bearing pressures are increased to $70,126,161$, and $245 \mathrm{kPa}$ with geogrid reinforcement, at similar settlement level and subgrade variations.

Variation of $I_{\text {fsg }}$ is presented in Fig. 16 for different foundation configurations ( $H=0.63$ to $2.19 D)$ having different subgrades $\left(c_{\mathrm{u}}=7\right.$ to $\left.60 \mathrm{kPa}\right)$, at two different levels of footing settlements $(s / D=12$ and $24 \%)$. The 


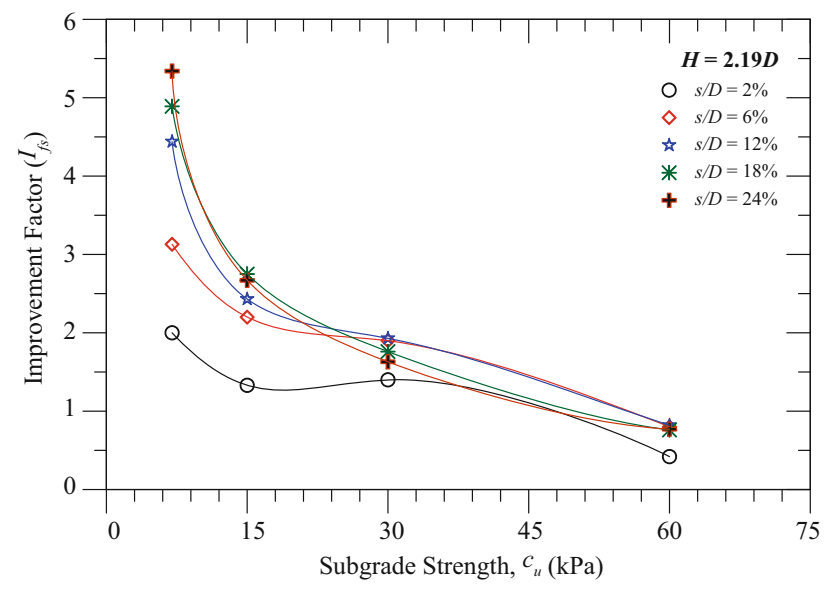

Fig. 14 Variation of $I_{\mathrm{fs}}$ for different $c_{\mathrm{u}}$ and $s / D(\%)$ at $H=2.19 D$

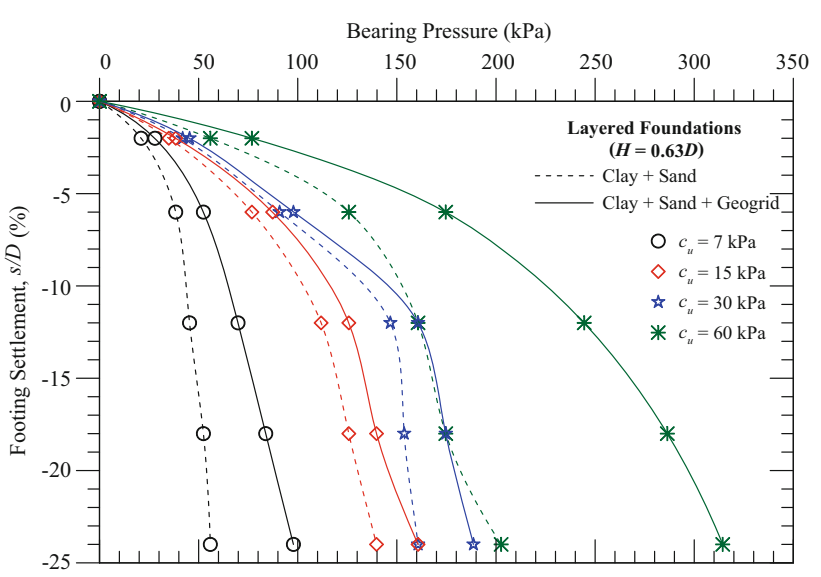

Fig. 15 Responses of unreinforced and geogrid-reinforced foundations of different $c_{\mathrm{u}}$ at $H=0.63 D$

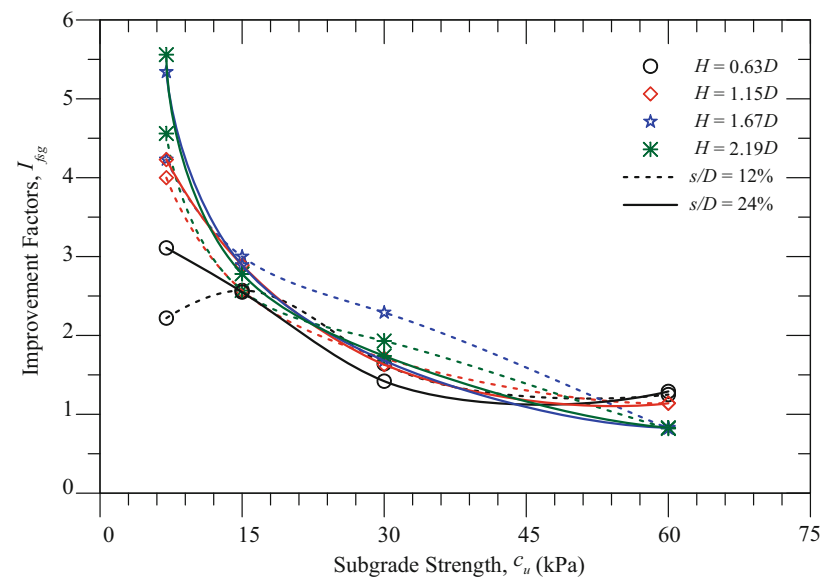

Fig. 16 Variation in $I_{\mathrm{fsg}}$ for varying $c_{\mathrm{u}}$ and $H / D$ at $s / D=12$ and $24 \%$

decreasing trend in improvement factor can be noticed which is irrespective of layer thicknesses. The effectiveness of planar geogrid was gradually decreased with

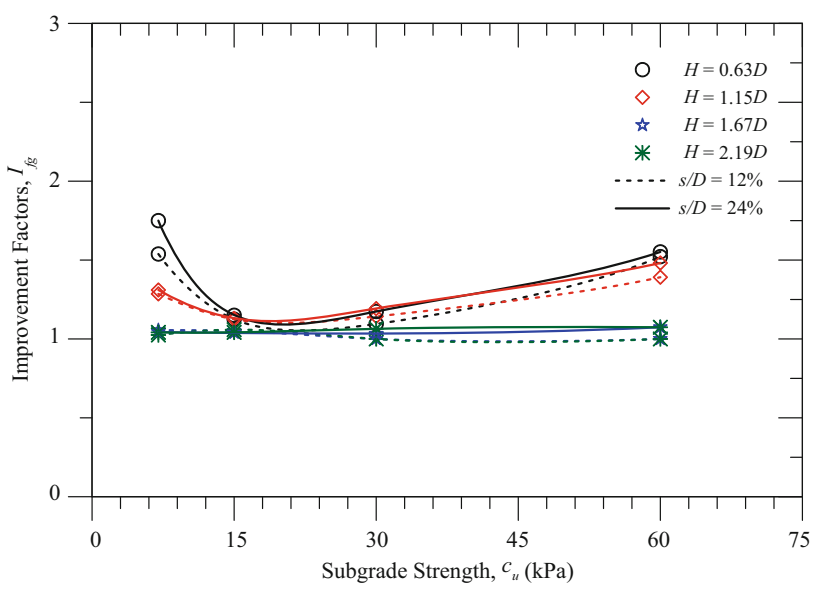

Fig. 17 Variation in $I_{\mathrm{fg}}$ for varying $c_{\mathrm{u}}$ and $H / D$ at $s / D=12$ and $24 \%$

subgrade strengths $\left(c_{\mathrm{u}}\right)$ which could be seen through $I_{\mathrm{fsg}}$. The improvement factor, $I_{\mathrm{fsg}}$, is found in the range of $1.33-5.56$ for $c_{\mathrm{u}} \leq 15 \mathrm{kPa}$; while, for comparatively stiffer subgrades $\left(c_{\mathrm{u}} \geq 30 \mathrm{kPa}\right)$, it is in the range of 0.58-2.29. The performance reduction is attributed to the restrained subgrade penetration which is responsible for insufficient membrane resistance generation and greater sand-squeezing from footing bottom.

The variation of $I_{\mathrm{fg}}\left(=q_{\mathrm{sg}} / q_{\mathrm{s}}\right)$, corresponding to similar foundation configurations, is presented in Fig. 17. The $I_{\mathrm{fg}}$ are in the range of $1.2-1.6,1.09-1.15$, and $1.08-1.19$ for $c_{\mathrm{u}}=7,15$, and $30 \mathrm{kPa}$. This indicates decreasing reinforcement contribution with increasing subgrade strength. However, it is seen from the figure that comparatively higher $I_{\mathrm{fg}}$, can be found for $c_{\mathrm{u}}=60 \mathrm{kPa}(H \leq 1.15 D)$ in the range of $1.25-1.64$. This anomaly in general trend is due to the definition of $I_{\mathrm{fg}}$, wherein, it is evaluated with respect to the bearing pressure of unreinforced foundations $\left(q_{\mathrm{s}}\right)$. In unreinforced configurations, the bearing pressures of layered foundations on $c_{\mathrm{u}}=60 \mathrm{kPa}$ were reduced as compared to homogeneous clay bed $\left(q_{\mathrm{s}}<q_{\mathrm{c}}\right)$. But with planar geogrid, higher bearing pressures were obtained i.e., $q_{\mathrm{sg}}>q_{\mathrm{c}}$ and $q_{\mathrm{sg}}>q_{\mathrm{s}}$. Therefore, the $I_{\mathrm{fg}}$ (i.e. $q_{\mathrm{sg}} / q_{\mathrm{s}}$ ) is magnified for $60 \mathrm{kPa}$ (as $q_{\mathrm{c}}>q_{\mathrm{s}}$ ), compared to the other subgrades $\left(c_{\mathrm{u}} \leq 30 \mathrm{kPa}\right)$. It can be stated that the planar geogrid is most effective in softer clay subgrades $\left(c_{\mathrm{u}} \leq 15 \mathrm{kPa}\right)$ and shorter layer thicknesses $(H \leq 1.15 D)$.

\section{Conclusions}

The results obtained indicate that the performances of foundation systems are largely dependent on the subgrade strength, thickness of the sand layer, and footing settlement level. In the case of foundation systems with unreinforced sand layer over clay subgrades, maximum improvement in 
bearing pressure was obtained for very soft subgrade $\left(c_{\mathrm{u}}=7 \mathrm{kPa}\right)$, in the range of 5.34 fold, as compared to the corresponding homogeneous clay bed. Whereas, the same for the comparatively stiffer clay subgrade, having $c_{\mathrm{u}}=$ $30 \mathrm{kPa}$, was 2.29 only. It is concluded that the improvement factor for bearing pressures in the layered foundation systems decreases with increase in subgrade strength.

The bearing pressures of layered foundation systems were increased for the geogrid reinforcement placed at the sand-clay interface. The benefits of the interface geogrid are attributed to the membrane resistance which enhanced with mobilized strain level through footing settlement. However, geogrid-induced improvements were reduced with increase in layer thickness of the unreinforced sand and stiffness of the underlying clay subgrades, due to insufficient strain mobilization for the membrane actions.

Comparing the obtained results, it can be concluded that the improvement factors for bearing pressures of the unreinforced and/or reinforced layered foundation systems decreases with increase in layer thickness and subgrade strength. The optimum thickness of sand layer, for both the configurations, giving optimum performance can be concluded as $1.67 D$, which was mostly effective for softer clay subgrades $\left(c_{\mathrm{u}} \leq 15 \mathrm{kPa}\right)$.

\section{References}

1. Vidal H (1969) The principle of reinforced earth. Highway Research Record, 282, Washington, D.C

2. Binquet J, Lee KL (1975) Bearing capacity tests on reinforced earth slabs. J Geotech Eng Div ASCE 101(12):1241-1255

3. Love JP, Burd HJ, Milligan GWE, Houlsby GT (1987) Analytical and model studies of reinforcement of a layer of granular fill on soft clay subgrade. Can Geotech J 24(4):611-622

4. Huang CC, Tatsuoka F (1990) Bearing capacity of reinforced horizontal sandy ground. Geotext Geomembr 9(1):51-82

5. Omar MT, Das BM, Yen SC, Puri VK, Cook EE (1993) Ultimate bearing capacity of rectangular foundations on geogrid-reinforced sand. Geotech Test J ASTM 16(2):246-252

6. Sitharam TG, Sireesh S, Dash SK (2005) Model studies of a circular footing supported on geocell-reinforced clay. Can Geotech J 42(2):693-703

7. Akinmusuru JO, Akinbolade JA (1981) Stability of loaded footings on reinforced soil. J Geotech Eng Div ASCE 107(6):819-827

8. Giroud JP, Noiray L (1981) Geotextile reinforced unpaved road design. J Geotech Eng Div ASCE 107(9):1233-1254

9. Fragaszy RJ, Lawton E (1984) Bearing capacity of reinforced sand subgrades. J Geotech Eng ASCE 110(10):1500-1507

10. Guido VA, Chang DK, Sweeney MA (1986) Comparison of geogrid and geotextile reinforced earth slabs. Can Geotech $\mathbf{J}$ 23:435-440

11. Kim SI, Cho SD (1988) An experimental study on the contribution of geotextiles to bearing capacity of footings on weak clays. In Proceedings of International Geotechnical Symposium on Theory and Practice of Earth Reinforcement, Fukuoka, Japan, pp 215-220
12. Samatani NC, Sonpal RC (1989) Laboratory tests of strip footing on reinforced cohesive soil. J Geotech Eng ASCE 115(9):1326-1330

13. Mandal JN, Sah HS (1992) Bearing capacity tests on geogridreinforced clay. Geotext Geomembr 11(3):327-333

14. Shin EC, Das BM, Puri VK, Yen SC, Cook EE (1993) Bearing capacity of strip foundation on geogrid reinforced clay. Geotech Test J ASTM 16(4):534-541

15. Khing KH, Das BM, Puri VK, Cook EE, Yen SC (1993) The bearing capacity of a strip foundation on geogrid-reinforced sand. Geotext Geomembr 12(4):351-361

16. Khing KH, Das BM, Puri VK, Yen SC, Cook EE (1994) Foundation on strong sand underlain by weak clay with geogrid at the interface. Geotext Geomembr 13(3):199-206

17. Das BM, Omar MT (1994) The effects of foundation width on model tests for the bearing capacity of sand with geogrid reinforcement. Geotech Geol Eng 12(3):133-141

18. Michael AT, Collin JG (1997) Large model spread footing load tests on geosynthetic reinforced soil foundations. J Geotech Geoenviron Eng ASCE 123(1):66-72

19. Alawaji HA (2001) Settlement and bearing capacity of geogrid reinforced sand over collapsible soil. Geotext Geomembr 19(2):75-88

20. Sitharam TG, Sireesh S (2004) Model studies of embedded circular footing on geogrid reinforced sand beds. Ground Improv $8(2): 69-75$

21. Basudhar PK, Saha S, Deb K (2007) Circular footings resting on geotextile reinforced sand bed. Geotext Geomembr 25(6):377-384

22. Latha GM, Somwanshi A (2009) Bearing capacity of square footings on geosynthetic reinforced sand. Geotext Geomembr 27(4):281-294

23. Rajyalakshmi K, Madhav MR, Ramu K (2012) Bearing capacity of reinforced strip foundation beds on compressible clays. Indian Geotech J 42(4):294-308

24. Jha JN, Choudhary AK, Gill KS, Shukla SK (2013) Bearing capacity of a strip footing resting on reinforced fly ash slope: an analytical approach. Indian Geotech J 43(4):354-366

25. Kazi M, Shukla SK, Habibi D (2015) Effect of submergence on settlement and bearing capacity of surface strip footing on geotextile-reinforced sand bed. Int J Geosynth Ground Eng. doi:10. 1007/s40891-014-0006-y

26. Kazi M, Shukla SK, Habibi D (2015) An improved method to increase the load-bearing capacity of strip footing resting on geotextile-reinforced sand bed. Indian Geotech J 45(1):98-109

27. Kumar A, Saran S (2001) Isolated strip footings on reinforced sand. J Gotech Eng SEAGS 32(3):177-189

28. Kumar A, Walia BS, Saran S (2005) Pressure-settlement characteristics of rectangular footings resting on reinforced soil. J Geotech Geol Eng 23:469-485 Springer

29. Kumar A, Walia BS, Saran S (2007) Pressure-settlement characteristics of rectangular footings resting on reinforced layered soil. Int J Geotech Eng 1(1):81-90 J. Ross Publishers

30. Biswas A, Krishna AM, Dash SK (2013) Influence of subgrade strength on the performance of geocell-reinforced foundation systems. Geosynth Int 20(6):376-388

31. Dash SK, Sireesh S, Sitharam TG (2003) Model studies on circular footing supported on geocell reinforced sand underlain by soft clay. Geotext Geomembr 21(4):197-219

32. Meyerhof GG (1974) Ultimate bearing capacity of footings on sand layer overlying clay. Can Geotech J 11(2):223-229

33. Terzaghi K (1943) Theoretical soil mechanics. Wiley \& Sons, New York

34. Terzaghi K, Peck RB, Mesri G (1996) Soil mechanics in engineering practice. John Wiley and Sons, New York 